\title{
Food agencies as an institutional response to policy failure by the UK and the EU
}

\author{
David Barling
}

\section{Introduction}

The UK public's confidence in the quality of the modern food supply, and in the governance of that supply, took a buffeting through a series of food safety crises in the 1980s and 1990s. The much-quoted list ranged from pesticide residues to salmonella in eggs, to BSE (which was estimated as a cost of over $£ 4$ billion to the public purse) and E.coli 0157 . The internal market of the EU shared in some of those incidents, notably that of BSE, and added others such as dioxin contamination and nitrofurans in feed and poultry in the 1990s and into the early 2000s.

At both the UK and the EU level of governance there was a perception of policy failure over the safety of the final food product emerging from the supply chain. The safety concerns reached back along the food chain to the production inputs on the farm, such as animal feed, and to processing and manufacturing practices. The response at both EU and national levels has been to bring forward a phase of institutional change and reordering with regard to food safety and standards with an emphasis on the safety and health of the consumer. The EC rearranged its food safety responsibilities, putting them under the newly constituted Directorate General for Health and Consumer Protection, and began a process of revising and rationalising EU food laws and regulation. An independent European Food Safety Authority (EFSA) was also created. The UK introduced its own independent Food Standards Agency (FSA) in 1999, hiving off responsibilities from the Ministry of Agriculture, Fisheries and Food (MAFF). The final break-up of MAFF took place in June 2001, with its remaining responsibilities being reconstructed within a new Department for Environment, Food and Rural Affairs (DEFRA), in the wake of the foot-and-mouth crisis. The political resonance of foot-andmouth as a bio-security threat lay in its impact on the perception of the food quality and economic value of UK and European meat rather than in its animal health implications alone.

A further product of the response to policy failure in the UK was a review of the future of farming and food in the UK, called the Curry Commission, which led in turn to DEFRA's Strategy for Sustainable Farming and Food 
(2002) laying out a reordering of policy. At the EU level the hitherto largely autonomous agricultural policy process, as enshrined in the Common Agricultural Policy (CAP), is also evolving through a long and ongoing period of policy adaptation. The signalled intention of the next phase of CAP reform is to shift supports more substantially away from production subsidies to the (largely non-production) rural development pillar supports, part of the move to a so-called multifunctional model for agriculture. This shift incorporates an agricultural subsidy system, based not only on quantitative measures of production or acreage and livestock head-count but on qualitative measures such as wildlife, plant and landscape conservation, animal welfare, rural business diversification and food quality and diversity. The UK has endorsed this approach, and it is evident in the details of the Strategy for Sustainable Farming and Food (DEFRA 2002).

The EC depicted the introduction of EFSA as a part of a comprehensive 'farm to fork' recasting of food safety, including the aforementioned reorganisation and recasting of European food laws. In addition, the EC is beginning to frame a policy link between food safety and standards and in turn food production supports in terms of food quality, connecting food production with consumption and vice-versa. The role of food provenance, as an indicator of quality and market value, is a feature of the linking of production to consumption. The importance of the competitiveness of UK farming and food is another key theme of DEFRA's Strategy for Sustainable Farming and Food, and is addressed, in part, in the value-added aspects of food quality from the $\mathrm{UK}$ and its regions.

The food agencies introduced in the UK and at the EU level are located within these wider policy configurations. They are part of the authorities' response to policy failure in agri-food governance. The key issues here are to examine the ways in which these food agencies, through their remits and scope (and subsequent action), represent institutional responses to wider food quality concerns. How are those concerns being portrayed and interpreted through the particular institutional configurations of these agencies? Where do the agencies fit within the differing, but linked, policy responses to perceived failures at UK and EU levels? To what extent do they differ in terms of their remit and scope, and in their relationship with other (and the new) political institutions? How has the establishing of the agencies addressed the problems of food quality? Given that the FSA pre-dated EFSA, what can be gleaned from the first three years of the FSA's operation? What is the likely relationship between the FSA (an institution of a member state) and EFSA (an EU institution)? How are the linkages between the policy developments at EU and UK levels to be understood?

The analysis here presented is framed by an institutionalist approach that draws on the emerging literature on the interlinking of multiple levels of governance in the explanation of the shaping of agri-food policy decisions in national and international arenas. The juxtaposition of national level change and of EU level reform allows the multilevel governance dimension to be 
incorporated and more fully articulated, particularly as it has impacted on UK policy formulation and institutional reform. An explanation of EU level reform is a necessity, in any case, as it sets a framework for response at the national level and points to possible future policy-making dynamics between the distinct levels. Equally, it allows for the diverse (albeit linked) circumstances and influences shaping the two agencies to be explored and for the approaches to food safety and food quality to be compared and contrasted. In the case of the UK, the FSA has set up devolved management boards for Scotland, Wales and Northern Ireland under its sub-national devolution of government. Multilevel governance incorporates those levels, though the focus of the analysis presented here remains the national UK-EU interaction, within the context of the evolving international governance of food and agriculture.

\section{Multilevel governance and strategic policy decisions}

The determination of some key decisions by the EU and its member states has been explained within a framework of multilevel governance, in the form of two-level or multilevel strategic bargaining and decision-making (Moravcsik 1993; Marks et al. 1996; Scharpf 1997). Domestic considerations impact on international decisions, but international decisions also catalyse domestic considerations (Putnam 1988). There may be a range of decisions taking place simultaneously, according to different institutional rules and in slightly different domestic policy contexts, each of which is shaping the others to some extent. In agriculture, the negotiation of the GATT Uruguay Round agreements and the so-called McSharry reforms of the CAP (achieved in 1992) took place simultaneously and involved international (including the USA and the Cairns group of commodity exporting countries), EU and national level bargaining games (Paarlberg 1997; Moyer and Josling 2002).

The Agenda 2000 reforms of the CAP were shaped, at least in part, by the terms of the trade rules laid out in the General Agreement on Trade and Tariffs (GATT) Uruguay Round's Agreement on Agriculture (hereafter, AoA; Moyer and Josling 2002; Barling 2003). The AoA was designed to begin the liberalising of domestic agricultural supports. The different types of domestic support were subject to distinct arrangements under the AoA. These differing arrangements are known as 'boxes' and are colour-coded. The agreement allowed for government supports for agriculture that have 'no, or at most minimal, trade distorting effects or effects on production' and that lacked 'the effect of providing price support to producers'. Such supports were seen as truly decoupled from production and so were put into the socalled 'green box'. Direct payments to farmers that seek to reduce production under Agenda 2000, such as arable area and livestock headage payments, are also allowed under the AoA. However, such supports are supposed to be phased out over a period of time and were put in the 'blue box'. There were several ambiguities in the wording of the AoA, reflecting the fraught diplomatic negotiations and compromises that produced it, and a 
review was built in from 2000 which was to be undertaken by 2003. That review was still incomplete by mid-2003. Its completion was seen as being contingent, in part, on the mid-term review of the Agenda 2000 reform of CAP and, with it, the agreement of a common EU position for the AoA's review (Barling 2003). Progress in further liberalising developed countries' agricultural subsidies is seen as essential for the completion of the so-called Doha, or development round of the WTO trade liberalisation negotiations. This process of mutually contingent regime reviews is illustrative of the context within which multilevel governance leads to strategic policy choices, and multilevel bargaining and game-playing, by states and other participants (such as international organisations).

In the case of the CAP Agenda 2000 mid-term review the EC has signalled a further shift away from production subsidies, a process termed 'decoupling', towards more qualitative supports. The EU has sought to frame those supports as 'green box'-compliant and non- or minimally trade-distorting under the AoA. The EC has described these supports as reflecting a multifunctional model of agriculture, one that 'covers the protection of the environment, and the sustained vitality of rural communities, food safety and other consumer concerns' (WTO 2000: 1).

The UK Government has supported the EC's policy direction on CAP reform. The introduction of DEFRA as a governmental department merging environment with agriculture and rural affairs marked an institutional affirmation of this policy approach of wider agri-environment and rural development supports for British agriculture. Hence, an important area of strategy calculation informing the UK's response to policy failure over food quality (from BSE and its antecedents to foot-and-mouth disease), was shaped by calculations derived from the directions of trade liberalisation agreements and CAP reform.

Strategic decision-making, of course, is just that. It is highly contingent on calculations of the policy directions at other levels playing out in certain directions. The momentum-shifting permissible state supports towards rural development under the mid-term review of CAP have had their momentum jarred by an initial Franco-German agreement to slow down the pace of such transfers to beyond the mid-term review (Grant 2003). Similarly, exactly which kinds of supports are indeed green box-compliant is still open to interpretation - for example, organic farming supports (Barling 2003). The subsequent institutional reforms at $\mathrm{EU}$ and $\mathrm{UK}$ levels are located within these broader strategic policy calculations and directions.

\section{New institutionalist approaches to analysing policy response and food quality}

The new institutionalist schools of analysis place an emphasis on the influence of institutions, their operating procedures and practices as shaping factors of public policy. Policy network formations and the pressures applied by external interests are not seen as the only determinants of the final shape of 
policy outcome. The norms and operating procedures of institutions can also shape the final nature of policy. Within new institutionalist theory, historical institutionalism stresses that certain path dependencies may be put in place during periods of institutional creation. That is, there are critical junctures in the historical development of policy where policy moves in a different direction, creating a path dependence that subsequently is difficult and costly to reverse. The creation of new institutions can be a key component in setting forward a new path for policy consideration - such institutions becoming the part of the new framework setting the boundaries within which policy will be made. Institutions become the "carriers of history", with the ideas behind early policy choices continuing to serve as parameters in which actors respond to new socio-economic challenges' (Jones and Clark 2001: 7). At this relatively early stage we might consider the extent to which the enabling legislation of the agencies reflect policy choices that are likely to endure. In the case of the FSA, moreover, we can take the first three years of the institution's operation and consider the extent to which such policy choices have evolved and the paths they have taken.

The creation, respectively, of the FSA and the EFSA occurred at a juncture when perceptions of policy failure were acknowledged at UK and EU governmental levels. My analysis seeks to explore more fully this period of institutional reform and the rationales behind the setting in place of these new institutions and the other institutional and policy reforms that have occurred alongside them. The institutional configurations set up during this period will play a role in shaping policy in the near to mid-term future, at least. The policy ideas that have shaped the introduction of these institutions can begin to be unravelled.

The reform period that was embarked on at the turn of the millennium is in certain ways a significant departure, yet one which remains (at this stage) a hesitant and variable approach to food quality in policy terms. The immediate, or priority, policy concern regarding food quality has been one of food safety, notably microbial food safety, for the consumer. Beyond that, there are distinctions to be found at the UK and EU levels, but there is some commonality also. Food authenticity and provenance are emerging issues. The valueadded aspects of food quality within a liberalising (but still far from perfectly competitive) international trade are recognised, as part of a linking of food production to its consumption. Such recognition is framed within an adherence to the liberal trade paradigm, where national (or regionally integrated) economic areas seek competitive advantage through the realisation of such added value. The environmental and cultural aspects of food production have been partially integrated into this notion of food quality also, as the CAP reform process indicates. The public health consequences of nutrition and diet are beginning to be addressed in a cautious fashion in the UK, and there are signs of policy movement on an area that has lacked any clear strategic vision in the recent past (Lang and Rayner 2003). The picture on nutrition and diet remains somewhat fragmented at the EU level, although there have 
been initiatives, notably from the French presidency of the EU in 2000 (CEC 2000a). The nutrition remit of EFSA is, however, weak.

EFSA does have a remit to look right along the food supply chain. The FSA's remit is less extensive, as it starts after the farm gate; but ambiguities have become evident in this regard. In the case of the EU, the imperatives of managing the single market and underpinning the legitimacy of the integrationist project are drivers for the policy and institutional responses to the failures over food safety and quality. The setting up of the agencies and an assessment of their early inception are presented below in the context of the wider reforms taking place in food safety and food policy in the UK and at the EU level, respectively.

\section{Food safety regulation in the 1990s: setting private and public sector food standards}

The creation of the FSA was the first significant stage in a revision of the institutions of food governance in the UK. A previous response under the Conservative Governments had been to endorse self-regulation by the food industry with the 1990 Food Safety Act. That Act emphasised the 'due diligence' defence which requires a person to have taken 'all reasonable precautions and exercised all due diligence'. Food safety became more process-driven with the introduction of workplace regimes centred on hazards analysis critical control point (HACCP) practices. These instruments placed the onus on the supply chain to self-improve and to show that it was doing so.

This approach has been reinforced by the commercial realities of modern food supply chains, especially increased corporate concentration along the supply chain, notably in retailing but also in manufacturing and, increasingly, catering. These developments have brought what might be broadly described as a dual regulation to the agri-food system. Private forms of regulation through grading, standards and contract specifications have rapidly evolved with the increased international sourcing of foods and food and feed ingredients. The private sector has led the way in consumption-end-led regulation of the food supply chain, often in the absence of adequate public regulation (Reardon and Farina 2001; Reardon and Berdegué 2002). The main form of private (or quasi-)regulation from the public and private sectors has been process-based around systems, such as 'good manufacturing practice' (GMP) and HACCP. Large multinational companies have introduced HACCP in the sourcing of food ingredients, as Unilever has for its coconut production suppliers in Brazil (Reardon and Farina 2001). Indeed, internationally, governments beyond the UK have rapidly adopted HACCP as a self-regulatory instrument, for example in the fisheries sector (Lazer 2001). The other form has been product characteristics such as grading and standards, or maximum residue levels (MRLs) often validated by the State.

Dual regulation, public and private, has crossfertilised, leading to a degree of hybridisation. This has occurred through a mix of state cooption of the 
private sector and state adaptation of private sector standards or instruments. An example of the former is the application of the Home Authority Principle for the food safety regulation of corporate supermarkets in the UK (Flynn et al. 1999). The private sector has led the way in a range of food quality controls through the setting of standards, such as organic farming and food standards, the development of new quality systems such as farm assurance schemes and product-tracing, or traceability, systems. The rapid development of private sector standard-setting has left public sector regulation in its wake, and has led to a catch-up process of the overseeing and review of such standards for new institutions such as the FSA.

The Labour Party's manifesto in 1997 made two main food-specific electoral promises. The first was to reform MAFF by setting up a food standards body. The second promise was to reform the CAP. The Labour Party under the Atlee Government had introduced in 1947 the Agriculture Act that established the framework for state support of and subsidy for farming over the next half-century. In its long period in opposition from 1979 Labour promised to reduce that support. Also, Labour in opposition had learned to embarrass the Conservative Government for its poor food governance but was slow to formulate its own policy solutions in terms of a food agency. The Wishaw E.coli 0157 case in February 1997 spurred Labour to develop more detailed policy proposals (HMSO 1997). The Wishaw example showed that regulatory incompetence accompanied by appalling standards of hygiene in a butcher's shop (where a de facto meat factory also functioned) could have disastrous public heath consequences, as well as political fall-out. Tony Blair, as leader of the Opposition, commissioned Professor Phil James, then of the Rowett Research Institute, to produce a draft plan for a food agency, which was published the day before Labour's election to government (James 1997). A ministerial group on food safety was set up, followed by a white paper from MAFF in January 1998, the Food Standards Act in 1999, with the FSA coming into being in 2000 .

\section{The FSA and policy reform in the UK}

The main aim of the FSA as set out in the Food Standards Act (HMSO 1999: 1) was 'to protect public health from risks which may arise in connection with the consumption of food (including risks caused by the way in which it is produced or supplied) and otherwise protect the interests of consumers in relation to food'. Its key task was to 'rebuild public trust' in the Government's handling of food safety (Krebs 2003a). The FSA was made accountable to the secretary of state at the Department of Health (DH). The close relationship between food producer and government department, where MAFF was both sponsor and regulator of the farming and agricultural supply industries, was broken. The FSA could claim to be free from the direct sponsorship of any sector of the food industry. It was established as an agency of the crown, with an arm's length independence of the sponsoring government department, 
similar to the Health and Safety Executive. Sir John Krebs (an Oxford University zoologist) was appointed chair of the FSA, with the chief executive appointed from the $\mathrm{DH}$ and its initial membership drawn largely from the Food Standards and Safety section of MAFF.

On matters connected with 'food safety or other interests of consumers in relation to food', the FSA had both an advisory and an informative function, and a responsibility for 'developing policies (or assisting in the development by any public authority of policies)' (HMSO 1999: 3). These responsibilities extended also to animal feed. In addition, the FSA was given the executive tasks of monitoring the enforcement of food and feed safety, which included absorbing the Meat Hygiene Service. The functions of risk assessment and risk management were combined, with the FSA seeking to act as an authoritative voice. Risk assessment was to be provided by the network of scientific advisory committees concerned with food that had been moved from MAFF and the DH to be under the sponsorship of the FSA. In short, the FSA was given a policy-making role as well as policy advice and enforcement roles.

The FSA's other key function of protecting 'other interests of consumers in relation to food' was defined in the white paper as encompassing 'issues relating to the compositional quality of food, the choice of foods available and the information on which choices can be made' (MAFF 1998: 8). This remit has allowed it to undertake a range of policy reviews and consultations in areas such as food authenticity and labelling where the private sector is already well advanced. Reviews of farm assurance schemes, advertising claims and quality claims (such as on 'freshness' of food), and policy advice on traceability and authenticity, have been undertaken by the FSA.

In relation to the food chain the remit covers risks in how food (and feed) is produced or supplied. The white paper offered the qualification that in 'some areas such as nutrition policy and food safety issues which relate to farming practices, Health, Agriculture and Environment Departments will retain important policy and statutory responsibilities' (MAFF 1998: 8). A senior civil servant from the old MAFF who had been involved in the drafting of the legislation felt the intention was for the role of the FSA to stop at the farm gate. The white paper gave the example of BSE controls where the FSA would be responsible for controls on the human food chain from the slaughterhouse onwards (MAFF 1998: 19). Areas such as veterinary medicines and pesticides remained under the purview of MAFF, not of the FSA. The hand of MAFF was clearly visible here, contradicting the recommendation of James that the remit should be right along the food chain, from farm to fork, to include these responsibilities (James 1997; Lang et al. 1997). The white paper felt that responsibilities for pesticides and veterinary medicines would 'risk diverting it from its essential role of protecting public health'. MAFF felt that the proposals nevertheless allowed the FSA to intervene 'where farming practices impact on the safety of food' (MAFF 1998: 17).

In practice, the FSA has been able to articulate on food safety and quality where production and process methods are a defining characteristic of the 
food, while absolving itself of the need to consider other production-related factors such as environmental or animal welfare impacts of production. This has been illustrated by the FSA's stances on, respectively, organic farming and food, and GM crops and food, issues considered in more detail below.

The FSA has prioritised its food safety function during its first three years with a particular focus on micro-organisms and microbiological safety. As Krebs has acknowledged: '[in] the past three years we have focused very much on what might be described as "traditional" issues of food safety: chemical contaminants, BSE, food poisoning, and so on' (Krebs 2003a). The FSA was given increased funding by the Treasury, having set itself the target of reducing food-borne illness by 20 per cent over 5 years (i.e. by 2006). This was an ambitious target, as after three years the spread of Campylobacter in UK poultry was reported to be on the rise (Environmental Health News 2003). James (1997) had described policy over chemical contaminants as chaotic, and retail industry insiders have complained that there is still a lack of prioritisation on chemical contaminants by the FSA, such as a listing of their importance in safety terms and prioritising those that should be minimised or eliminated.

The FSA was given a role in nutrition policy. James (p. 33) had given this role a very high priority, suggesting that the FSA should be called the Food and Health Commission to emphasise the importance of integrating nutrition and diet policy within its remit. The white paper was more circumspect, dividing nutrition policy responsibilities between the DH and the FSA. The DH retained the public health functions, such as the links between diet and health, including behavioural and lifestyle issues where nutrition is an important factor; while the FSA was ascribed functions relating to food information needed by the public. The responsibility for the interface between these two areas was shared.

The DH has retained pre-eminence on nutrition and diet policy, and has overseen a range of initiatives on food and diet, although this has led to little in the way of grand or strategic thinking and action (Lang and Rayner 2003). The FSA board approved a joint DH-FSA Nutrition Forum in March 2001 as part of its nutrition strategic framework (FSA 2001a). This stakeholder body has remained a discussion and information exchange forum. It does not have an advisory role and has not put forward policy recommendations, unlike its predecessor under the DH - the Nutrition Taskforce. During its first three years, it remained unclear where and how the FSA's remit would integrate with health strategies at the $\mathrm{DH}$ and at regional, local and community levels (Lang and Rayner 2003).

The policy review undertaken by the Curry Commission and the subsequent Strategy for Sustainable Farming and Food (DEFRA 2002) did address food and health issues, with a focus on England. At the devolved levels of Scotland and Wales, nutrition and dietary strategies were formulated by 2003, leaving England without an equivalent and, more confusingly, no overall plan for the UK. A cross-departmental food and health action plan was set in motion by DEFRA's strategy document. The plan was to be coordinated 
under a DH steering group chaired by the deputy-chief medical officer and included a range of other departmental and agency representatives (DEFRA 2002: 39). The outcome of this process in terms of the content and impact of the plan will be important and will reflect the extent to which pubic health becomes a component of the policy reformulation of food quality.

Krebs (2003a) signalled a change in emphasis on diet and nutrition policy in a speech to mark the FSA's three-year anniversary in April 2003: 'we will pay more attention than we have in the past to issues of diet and health'. The diet-related causes of mortality and morbidity through cardio-vascular disease and cancers, the problems of obesity and the evidence from the national diet and nutrition surveys were cited. The speech left unclear the extent of the FSA's intervention in this policy area: 'there is a fundamental question about how much of this area is down to individual choice, how much is down to the responsibility of industry and how much of it is down to the Government to legislate' (Krebs 2003a). Nonetheless, a coronary heart disease policy specialist described the speech as expressing an 'almost Damascene conversion' on the part of the FSA's chair. The FSA launched at the same time a highprofile campaign to reduce salt levels in the diet, focusing on getting the food industry to reduce the amount of salt in manufactured and prepared foods sold at retail and catering outlets, much to the industry's discomfort. However, the extent to which the FSA adopts a more interventionist role in diet and health remains to be seen. During its first three years the FSA has adopted a consumerist, market-based, approach to many issues of food safety advice, often stressing the role of individual preference and choice as opposed to a more fundamentally structural assessment of food safety and the food system. The ways in which the FSA and the DH address the interaction of individual choice, industry responsibility and government regulation will play a key role in determining the dietary health of the UK's population.

The new agency made a conscious attempt to change the culture and embrace consumer organisations and wider public consultation, in an effort to overcome perceived faults and bias in MAFF's operation and as part of the long task of rebuilding public trust. The goal was to restore consumers' confidence in food. To that extent there has been a transparent and consultative approach embracing a wide range of interests, including consumer groups, as the FSA has sought to pacify and incorporate consumer concerns. NGOs complain privately of 'consultationitis', being drowned by endless consultation after the main parameters of policy have been set. Industry groups have also expressed private frustrations at the lack of genuine openness in the policy formulation stage or, as one characterised it, 'transparency without openness'. Both consumer and industry groups are aware that the key to policy influence is to have inputs in the initial drafting stages of the process. To that extent the FSA has underlined its independence.

One area where there are signs that the FSA is considering a more transparent approach is in the processes for risk-assessment advice to allow for a clearer presentation of scientific uncertainties. The review of the expert 
committees suggested that meetings should be held in the open and that contrary scientific views should be considered. The scientific committees should provide a record of differences of opinion, of how and why decisions were reached, and of where inherent assumptions helped frame decisions. This could allow both for the uncertainties and for the framing assumptions around risk assessment to be more clearly acknowledged, leading to a more transparent and open risk-analysis process (Millstone and van Zwanenberg 2002).

Transparency turned to opacity in the FSA's consideration of the deeper implications of consumers' concerns regarding food safety and quality. The FSA's consumerist approach was reflected in the submission it made to the DEFRA-sponsored Curry Commission on the future of food and farming. Using its own 'Consumer attitudes to food safety' survey evidence (see FSA 2000a), it grouped consumer concerns on shopping for food into primary concerns (price, time and convenience) and secondary and more complex concerns (intensity of production, animal welfare and the environment) (FSA 2001b). The survey (FSA 2000a) also showed that a significant proportion of consumers had concerns, when prompted, about food-poisoning (59 per cent), BSE (55 per cent) and the use of pesticides on food (50 per cent). However, there was no discussion of the implications of the secondary concerns (which go beyond the moment of shopping) for the nature of the food system and consumers' concerns regarding the dominant production methods of conventional agriculture. Instead, the importance of maintaining regulatory control systems through the food chain was seen as the key to addressing these 'secondary concerns'.

The FSA's potential for performing an advisory role that examines the deeper-rooted links between the systems of food production, manufacture, trade, safety and consumption have not been taken up. Rather it has adopted a conservative and relatively narrow approach to its remit of protecting the consumer against 'risks caused by the way in which [food] is produced or supplied', effecting a defence of conventional or industrial agriculture and food production. To that extent it has been willing to take a more activist role: not exactly policy-making, but certainly effective policy promotion. For example, in the wake of an Advertising Standards Authority ruling on the accuracy of health claims made by organic food producers in 2000, the FSA issued a hostile position paper on organic foods. This stated that the FSA 'considers that there is not enough information available at present to be able to say that organic foods are significantly different in terms of their safety and nutritional content to those produced by conventional farming' (FSA 2000b: 1). The FSA, despite an enlarged research budget, initially declined to fund, entirely or in part, such work from its own research budget. Criticism of its stance led the FSA to hold a subsequent seminar to discuss research needs regarding organic foods.

DEFRA had begun to address the market potential (as well as the environmental benefits) of organic food and farming through increased subsidy and 
research support at the national level within the space afforded under the CAP. That support included the drafting of an organic action plan. In late 2002 and early 2003 Minister for the Environment Michael Meacher corresponded with Sir John Krebs seeking a declaration from the latter concerning the environmental benefits of organic food production over conventional agricultural methods. Krebs's initial response was to say that environmental issues were not part of the FSA's remit and that there were no discernible benefits regarding the final food product; also, that it was not the role of the FSA to promote organic food - thus maintaining the FSA's independence. By June 2003 this stance had been ameliorated somewhat, with the concession that organic food was relatively free from pesticides (Krebs 2003b).

The critical stance taken on organics was in contrast to a much more benign approach to the safety of GM food and consumers' needs. For example, the FSA adopted an oppositional stance to the wishes of consumer groups and the retail industry on the EC's proposal of regulation for the full traceability of GMOs in food and feed along the food chain. The FSA advised the UK Government to oppose the EC's proposals as unworkable, siding with some manufacturers and processors (notably in animal feed) and with the large-scale commodity exporters (such as the American Soybean Association, which had the backing of the US government). Conversely, the large-scale retailers had endorsed traceability of GM food and feed along the food chain, drawing up their own code of conduct and putting it into practice (Barling and Lang 2003a). The Consumers' Association food policy officer saw the FSA and its chair as 'having a complete blind spot on GM issues' (personal communication to the author). In part, the FSA was following the line of the Labour Government and endorsing its desire to promote biotechnology in the interests of national economic competitiveness (Barling and Henderson 2000). The FSA's chair is a member of the Cabinet Sub-Committee on Biotechnology for which the promotion of biotechnology is a key goal, according to a former minister and member of the panel (Hall and Vidal 2003). Yet, the Government's overriding desire to be able to endorse GM crops and ease their entry into the European market is running into the obstacles generated by the complexities of realising consumer preferences through management of the food supply chain. While the FSA and the Government have sought to block traceability of food and feed derived from GM sources, the large retailers have been left to fill the regulatory vacuum and provide this food quality control on behalf of their customers.

To some extent, the FSA was able to operate in the first 2-3 years in a relative policy vacuum. This vacuum was subsequently filled with the creation of DEFRA in June 2001 and with the completion of the policy review and the prime minister's endorsment of DEFRA's Strategy for Sustainable Farming and Food at the end of 2002. The policy review's remit had been bounded within the international trade paradigm, to advise the Government in a manner 'consistent with . . . increased trade liberalisation' (PCFFF 2002: 2). DEFRA sought to merge strategies for the efficiency of the UK agri-food 
sector and its economic competitiveness with the rural development and multifunctional agriculture agenda that the UK had endorsed under the terms of the AoA and the Agenda 2000 reform of CAP.

A Food Chain Centre was set up under the industry-sponsored Institute of Grocery Distribution, with initial priority given to the red meat supply chain and its export promotion and benchmarking along the supply chain. There was an emphasis on reconnecting with the market and 'that a drive for added value is likely to go hand in hand with the pursuit of higher quality and that quality will need to be recognised and verified to assured standards' (DEFRA 2002: 15). Local and regional foods were to be promoted by encouraging increased local supply to large retailers and caterers as well as through more innovative outlets such as public sector procurement and farmers' markets. Small local and regional producers of foods were to be supported by Food for Britain, a government-industry sponsored export promotion body. Assurance schemes, already prevalent in the private sector, were identified as important in re-establishing public confidence. The organic action plan was seen as a competitive move designed to reverse, over a period of time, the 70 per cent imported-30 per cent domestically produced organic food share in the UK market to 70 per cent home produced. The importance of harnessing new technology to the agri-food sector, including GM within a robust risk-assessment regime, was also stressed. The economic and farm and supply management difficulties of ensuring coexistence of GM crops and seeds with their organic and conventional equivalents were not discussed.

The support for a decoupling of state supports through the CAP from production subsidies to rural development and wider agri-environment supports were emphasised. Also, DEFRA addressed the importance of nutrition (see above), animal welfare (on food safety and economic grounds) and food safety (with reference to some of the main initiatives of the FSA). The overall scope of the strategy will demand a far more coordinated and integrated approach to food policy than shown previously by the UK Government (Barling et al. 2002). The FSA will be only one of the institutional players. There are gaps in the strategy and, of course, many intentions are yet to be realised. The tensions within the contemporary food system are many and their resolution may not be achieved by policies formulated within the trade liberalisation-economic competitiveness paradigm and multilevel governance boundaries set by the AoA-CAP reforms (Lang 1999; Barling and Lang 2003a). The response at the international level of the EU was to introduce institutional reforms also, including an international food agency in the form of EFSA that came into operation some three years after the FSA, alongside a significant policy review.

\section{Food safety reform at the international level: the EU and the creation of EFSA}

The reform of food safety in the EU has had a high a place on the policy agenda of the EC since the mishandling of the BSE crisis during the mid-late 
1990s. The European Parliament found the EC guilty of serious maladministration and threatened it with censure should it fail to act. Responding in 1997 the European Commissioner Jacques Santer acknowledged shortcomings in the protection of consumer health and promised radical reform of the EC's machinery. He called for 'nothing short of a revolution in our way of looking at food and agriculture' (Santer 1997). This set in train organisational reforms. In 1997 the EC's scientific committees were moved to the Consumer Protection DG, and two green papers were issued laying out plans for food safety reform and for a revision of EU food law (Barling 1998).

After the collapse of the Santer Commission in 1999, the new Prodi Commission kept food safety as a priority and furthered the reform process, including a reorganisation of the EC's DGs. The Consumer Protection DG was renamed Health and Consumer Protection (DG SANCO), taking over food safety and food law policy-making responsibilities previously housed in the DGs for, respectively, Industry and Agriculture. These services had also been responsible for promotion of the agri-food industries. A white paper on food safety, released early in 2000, spelt out more clearly the introduction of a wide-ranging consolidation and revision of European food law. It enumerated over eighty legislative revisions and actions to the body of EU food law. It also proposed the new EFSA that was created with a regulation in January 2002 , leading to the establishment of the agency in 2003. Continuing food scandals and controversies (e.g. dioxin contamination and GM foods) reinforced the importance given by the Prodi EC to food safety reform. This institutional reorganisation and renewed legislative agenda were part of a strategy by the EC to work towards the restoration of citizen confidence in the safety of the food supply in the EU. The ability of the single market to deliver safe food was seen as particularly important to the legitimacy of the European integration project, at a time when the next wave of EU enlargement was pending and the revision of EU governance was being formulated. European Commissioner for DG SANCO David Byrne described the EC's policy response as a three-pillared approach: the first pillar was an effective range of food safety legislation; the second pillar was creating EFSA to identify risk and communicate with the public; and the third, a more effective approach to official enforcement controls. Elsewhere in the speech EFSA was described as the 'cornerstone in our strategy' (Byrne 2002).

EFSA's mission, as laid out in the regulation (CEC 2002: L 31/12), is to 'provide scientific advice and scientific and technical support for the Community's legislation and policy in all fields which have a direct or indirect impact on food and feed safety. It shall provide independent information ... and communicate on risks.' The remit reaches along the whole food and feed supply chains, but the scientific opinions are limited to food safety only. The scope of EFSA does include scientific advice on human nutrition in relation to EC legislation, and assistance, at the EC's request, with communication on nutritional issues within its health programme. The original name for the body was European Food Agency, but 'Safety' was added to reflect a 
down-playing of the nutritional and dietary responsibilities that were previously accentuated to meet the desires of France during its tenure of the EU presidency in the latter half of 2000.

The scientific committees from SANCO were transferred to EFSA, being reconstituted and newly appointed as eight committees, coordinated by a scientific committee of the chairs plus six other members, a process completed by May 2003. A concern voiced by some of the members of the EC's scientific steering committee is that EFSA's scientific committees will become segregated from non-food scientific advice, prohibiting a holistic approach to food safety issues, where safety has been compromised due to external factors (EU Food Law Monthly 2003a). A DG SANCO official was quoted as expecting EFSA 'to be independent but not out of control' (van Zwanenberg and Millstone 2003: 36). While EFSA is responsible for risk assessment, risk management is seen as residing with the EC in DG SANCO and with the other elected political bodies of the EU, the European Parliament and the Council of Ministers. This is a crucial distinction in the EC's strategy to renew consumer faith in the EU's food safety institutions.

The strategy adopted by the EC with the creation of EFSA is not without potential flaws. The attempt to make a demarcation between risk assessment and risk management is difficult as the boundaries between the two are by no means clear. There are often inherent management decisions in the framing of the ways that risks are assessed, and the extent to which uncertainties are acknowledged. The FSA has suggested a more transparent and open process of acknowledging framing and assumptions and uncertainties. The danger is that EFSA and SANCO will not be significantly transparent, and that this will undermine the authority of the new body. Similarly, the role of risk communication, given to EFSA, but in management terms shared with DG SANCO (that is, shared by the assessors and the managers) could be problematical (van Zwanenberg and Millstone 2003).

The creation of EFSA comes at a time when most of the EU member states have either created or reformed their national food agencies. Co-ordination between and across national bodies will be a key issue. In some cases (e.g. the UK's FSA) these food agencies embody both the risk assessment function with risk management, while in others (France's AFSSA) they follow EFSA role. The task of coordinating national viewpoints is the Advisory Forum's, the intergovernmental arena for resolving differences which will bring the competent national authorities together at EFSA. This is a potentially important forum and will almost inevitably see interplay between risk-assessment and risk-management issues. At the outset, EFSA's executive director (the former chief executive of the FSA) has sought to have the agenda of the Advisory Forum's meeting kept secret, offering publication of the minutes at a later date (EU Food Law Monthly 2003b). The cross-over between risk assessment and risk management may well become evident in the debates arising within this forum.

Its management board may assist EFSA to establish its independence from the EC over time. The national or inter-governmental dimension of EU 
policy has also appeared in the appointment of the fifteen-person board of EFSA, each drawn from a different member state, described by one insider as an inter-governmental 'carve-up' (Barling and Lang 2003b). The board members also represent different categories of stakeholder, to some extent. There are seven civil servants, two farming representatives and two manufacturing industry representatives, with one representative from each of medicine, retail, and consumer interests.

The reform of EU food legislation, as laid out in the white paper, covered a wide range of regulatory initiatives and revisions. In particular, food and feed hygiene legislation and food control enforcement were prioritised, as were labelling reforms (allowing nutritional and health claims to be made) to enhance consumer choice. The general principles and requirements of European Food Law Regulation 178/2002 laid down the key principles for legislative reform. Two related principles are the adoption of a 'farm to table', or whole-food chain, approach, and that food business operators should bear primary responsibility for food at all stages along the chain. Food operators have the responsibility to inform the relevant authorities of any safety concerns they may have over foodstuffs. Such concerns should be scientifically based. Consumer protection is supported by the adoption (as a new principle in food safety law) of the principle of traceability right along the food chain with responsibility again being held by the operator at each stage. The effectiveness of this legislation is hard to predict, as it might be difficult for food operators to be always clear about the safety of some product they are handling. To be effective, the regulation may need to be buttressed by further laws that detail safe levels for additives, contaminants and residues in food composition and it will contain the same food operator responsibilities (Hagenmeyer 2002).

The EC is seeking to strengthen its overseeing of food law enforcement and control at national levels. Commissioner Byrne announced a new regulation on Official Food and Feed Controls legislation (COM 2003: 52) in February 2003 that will strengthen the role of the EC and the Food and Veterinary Office in inspection control. It is due to be implemented in 2005. The most telling issue here is of the burden of the cost for these controls, as anything over and above normal inspection will be charged to the companies. The enlargement of the EU to include new member states from central and eastern Europe will place a further burden on the effective implementation of the rapidly evolving EU food laws.

Within these centralising trends in EU food safety, there are caveats being made that reflect a wider conception of food quality beyond the science-based hygiene enforcement approach. This wider conception is emerging in different areas of EU agri-food policy like scattered pieces of a yet to be completed jigsaw. The multifunctional model of agriculture embraces a greater diversity of farm activity as well as the public utility of traditional food production practices. A caveat that the EC has entered within its food standard-setting agenda is to allow for flexibility of standards on traditional foodstuffs. This 
reflects sensitivity regarding traditional foods on the part of Europe's rural peripheries. The revision of EU food law allows for specific rules for traditional foodstuffs to preserve their special methods of production. The CAP reforms intend to shift supports to rural development, and DG SANCO has stressed the need for rural development and sustainable agricultural programmes to support traditional food production. The EU has long sought the recognition of European legislation on the geographical indication of food within world trade rules, despite attempts by Australia and the USA to undermine their viability by challenging their applicability under the WTO's disputes procedure (Agra-Europe Weekly 2003). A discourse illustrative of attempts to link these policy streams was the Food Quality Dialogue overseen by the European commissioners for Agriculture and for Consumer Health and Consumer Protection. The dialogue took place both digitally and through a series of roundtable discussions held during 2001-2 in Brussels and member states. The dialogue served to link CAP reform to reform of standards-setting for food and for consumer desires for quality, while asserting food safety as the 'bedrock of quality' (EC 2002).

\section{Conclusions}

The multilevel governance approach has helped to delineate the parameters within which the perceived policy failures in agri-food governance in the UK and at the EU level have been addressed. The responses to policy failure in agri-food governance have been to overhaul the institutional arrangements and engage in processes of policy review. The introduction of food agencies has been a key element of the new institutional arrangements. The prime focus of the agencies has been on food safety. There has been differentiation between the UK and the EU in the remit and role of the agencies, as with differences in the division between risk-assessment and management functions, the scope of remit along the food chain and the extent of responsibilities beyond food safety. The food safety concerns of the public arising from the succession of food crises of the 1980s onwards have led to politicians scrambling to regain consumers confidence and trust. Consumers have become increasingly literate about the modern food supply chain and increasingly vocal about practices in that chain. The modern food system has thrown up some fundamental challenges for governance. Food at the point of consumption has become increasingly politicised. New production-consumption links are being demanded of policy makers. Yet there remains a reaction among policy makers to frame solutions in overridingly consumerist and individual choice terms and according to voluntary agreements. The deeper lying forces in the food system, corporate concentration, branding focused advertising, technological fixes, end of the chain value-adding, and so on, are not directly confronted.

The consumer choice metaphor has led to a tentative widening of the policy focus beyond core food safety issues to consider quality in terms of its market 
value, as witnessed by DEFRA's response to the strategy review of UK food and farming. There are signs that EU policy makers are making links between traditional food production practices in the rural periphery and market demand for quality and authenticity, with the multifunctional model of agriculture accommodating these notions of food quality. Yet the CAP is highly resilient. Its heritage is rooted in the defence of rural employment, a task it has managed as a desperate rearguard action against the advances of industrialised agriculture. The current reformulation contains echoes of past policies and a continued defence of the rural periphery, not withstanding the advance of the agri-environment agenda. In any case, food safety remains the 'bedrock', that is, the priority of the current policy response.

The impact of food nutrition and diet on health is a rapidly emerging issue on the policy horizon. This is an issue of public health demanding an approach based on populations. The agencies are struggling to find a response within their differing remits, cast in the role of support players. EFSA remains in the lay-by while DG SANCO seeks to re-engineer labelling messages and introduce effective traceability along the supply chain. The FSA is caught in the headlights between the triangle of individual choice, industry responsibility and government legislation. The FSA's chair has begun to use his advisory capacity to challenge industry over salt content in foods, but he may find his policy-making powers more persuasive if the FSA's institutional partners allow such interventionist gestures. Diet- and nutritionrelated health may become the consumer issue of the future, replacing the current discontent over food safety with a food quality issue of much greater consequence in morbidity and mortality terms (Lang and Rayner 2001). The policy landscape that is being shaped within the trade liberalisation-economic competitiveness paradigm and multilevel governance boundaries set by the AoA-CAP reforms looks an incomplete patchwork. The institutional paths for agri-food governance created at the beginning of the new millennium look unsuitable and in need of fresh construction, shaped by a new set of policy ideas for the longer haul.

\section{References}

Agra-Europe Weekly (2003), 'Analysis: what's in a name? The mounting row over geographical indications', 2051, 25 April, pp. A1-2.

Barling, D. (1998), 'In or out through the policy window? The European Commission and the reform of food safety', in Dobson, A. and Stanyer. J. (eds), Contemporary Political Studies 1998, Nottingham, Political Studies Association of the UK.

Barling, D. (2003), 'Impact of international policies (CAP) and agreements (WTO) on the development of organic farming', in den Hond, F., Groenewegen, P. and Straalen, N. van (eds), Pesticides: Problems, Improvements, Alternatives, Oxford, Blackwell Science.

Barling, D. and Henderson, R. (2000), 'Safety first? A map of public sector research into GM food and food crops in the UK', Centre for Food Policy Discussion Paper 12, London, Thames Valley University. 
Barling, D. and Lang, T. (2003a), 'A reluctant food policy? The first five years of food policy under Labour', Political Quarterly, 74(1), pp. 8-18.

Barling, D. and Lang, T. (2003b), 'Codex, the European Union and developing countries: an analysis of developments in international food standards setting', Report for the Rural Livelihoods Department of the UK Department for International Development, May, London, DfID.

Barling, D., Lang, T. and Caraher, M. (2002), 'Joined up food policy? The trials of governance, public policy and food systems', Social Policy \& Administration, 36(6), pp. 556-74.

Byrne, D. (2002), 'European quality policy for foodstuffs', Speech /02/55 at the Winter Meeting, Vienna, 11 February 2002, Brussels, European Commission.

CEC (2000a), Council Resolution on Health and Nutrition, 8 December, 14274/00, Brussels, Commission of the European Communities.

CEC (2000b), White Paper on Food Safety, COM (1999) 719 final, 12 January, Brussels, Commission of the European Communities.

CEC (2002), Regulation (EC) No. 178/2002 of the European Parliament and of the Council of 28 January 2002 laying down the general principles and requirements of food law, establishing the European Food Safety Authority and laying down procedures in matters of food safety, Official Journal of the European Communities, 1 February, L31/1-24.

DEFRA (2002), The Strategy for Sustainable Farming and Food: Facing the Future, London, HMSO.

EC (2002), Fischler and Byrne Final Round Table on Agriculture and Food, EU Institutions Press Release IP/02/700, 13 May, Brussels, European Commission.

Environmental Health News (2003), 'Chicken illness threatens FSA safety targets', 18(23), 20 June, p. 3.

EU Food Law Monthly (2003a), 'SSC warns that FSA could have a negative impact', 133 (January), pp. 5-8.

EU Food Law Monthly (2003b) 'EFSA's secret agenda', 137 (May), pp. 3-4.

Flynn, A., Marsden, T. and Harrison, M. (1999), 'The regulation of food in Britain in the 1990s', Policy \& Politics, 27(4), pp. 435- 46.

FSA (2000a), 'Consumer attitudes to food standards - United Kingdom', February, London, Food Standards Agency.

FSA (2000b), 'The Food Standards Agency's view on organic food - a position paper', August, London, Food Standards Agency.

FSA (2001a), 'Nutrition strategic framework: proposed action plan', Paper FSA 01/08/02, London, Food Standards Agency.

FSA (2001b), 'Submission from the Food Standards Agency to the Policy Commission on Farming and Food for England', London, Food Standards Agency.

Grant, W. (2003), 'Prospects for CAP reform', Political Quarterly, 74(1), pp. 19-26. Hagenmeyer, M. (2002), 'Modern food safety requirements - according to EC Regulation No. 178/2002', Zeitschrift für das gesamate Lebensmittelrecht, 4, pp. 443-59.

Hall, S. and Vidal, J. (2003), 'Meacher says health risks were played down', Guardian, 23 June.

HMSO (1997), Report on the Circumstances Leading to the 1996 Outbreak of Infection with E.coli 0157 in Central Scotland, the Implications for Food Safety and the Lessons to Be Learned, April, Edinburgh, HMSO.

HMSO (1999), Food Standards Act 1999, London, HMSO, chapter 28. 
James, P. (1997), Food Standards Agency: An Interim Proposal, 30 April, London, Department of Health.

Jones, A. and Clark, J. (2001), The Modalities of European Union Governance: New Institutionalist Explanations of Agri-Environment Policy, Oxford, Oxford University Press.

Krebs, J. (2003a), Speech to Westminster Diet and Health Forum Seminar, 3 April, London, Food Standards Agency.

Krebs, J. (2003b), 'Is organic food better for you?', speech given by Food Standards Agency Chair Sir John Krebs at the Cheltenham Science Festival, 4 June, London, Food Standards Agency.

Lang, T. (1999), 'The complexities of globalization: the UK as a case study of tensions within the food system and the challenge to food policy', Agriculture \& Human Values, 16(2), pp. 169-85.

Lang, T., Millstone, E. and Rayner, M. (1997), 'Food standards and the State: a fresh start', Centre for Food Policy Discussion Paper 3, London, Thames Valley University.

Lang, T. and Rayner, G. (eds) (2001), Why Health Is the Key to Farming and Food, Report to the Chartered Institute of Health, Faculty of Public Health Medicine, UK Public Health Association, National Heart Forum, London, Centre for Food Policy-UK Public Health Association.

Lang, T. and Rayner, G. (2003), 'Food and health strategy in the UK: a policy impact analysis', Political Quarterly, 74(1), pp. 66-75.

Lazer, D. (2001), 'Regulatory interdependence and international governance', Journal of European Public Policy, 8(3), pp. 474-92.

MAFF (1998), The Food Standards Agency: A Force for Change, Cm 3830, London, HMSO.

Marks, G., Hooghe, L. and Blank, K. (1996), 'European integration since the 1980s: state-centric versus multi-level governance', Journal of Common Market Studies, 34(3), pp. 341-78.

Millstone, E. and Zwanenberg, P. van (2002), 'The evolution of food safety policymaking institutions in the UK, EU and Codex Alimentarius', Social Policy \& Administration, 36(6), pp. 593-609.

Moravcsik, A. (1993), 'Preferences and power in the European Community', Journal of Common Market Studies, 31, pp. 473-524.

Moyer, W. and Josling, T. (2002), Agricultural Policy Reform: Politics and Process in the EU and US in the 1990s, Aldershot, Ashgate.

Paarlberg, R. (1997), 'Agricultural policy reform and the Uruguay Round: synergistic linkeage in a two-level game?', International Organisation, 51(3), pp. 413-44.

PCFFF (2002), Farming and Food: A Sustainable Future, London, HMSO.

Putnam, R. (1988), 'Diplomacy and domestic politics: the logic of two-level games', International Organisation, 42(3), pp. 427-60.

Reardon, T. and Berdegué, J. A. (2002), 'The rapid rise of supermarkets in Latin America: challenges and opportunities for development', Development Policy Review, 20(4), pp. 371-88.

Reardon, T. and Farina, E. (2001), 'The rise of private food quality and safety standards: illustrations from Brazil', International Food \& Agribusiness Management Review, 4(4), pp. 413-21.

Santer, J. (1997), Speech by the President of the European Commission in the debate on the report by the Committee of Inquiry into BSE, 18 February, Speech 97/39, European Parliament, Strasbourg, Brussels, European Commission. 
Scharpf, F. (1997), 'Introduction: the problem-solving capacity of multi-level governance', Journal of European Public Policy, 4(4), pp. 520-38.

World Trade Organisation (2000), EC comprehensive negotiating proposal, Committee on Agriculture Special Session, G/AG/NG/W/90, 14 December, Geneva, WTO.

Zwanenberg, P. van and Millstone, E. (2003), 'BSE: a paradigm for policy failure', Political Quarterly, 74(1), pp. 27-37. 